\title{
A percepção e o comportamento ambiental dos universitários em relação ao grau de educação ambiental
}

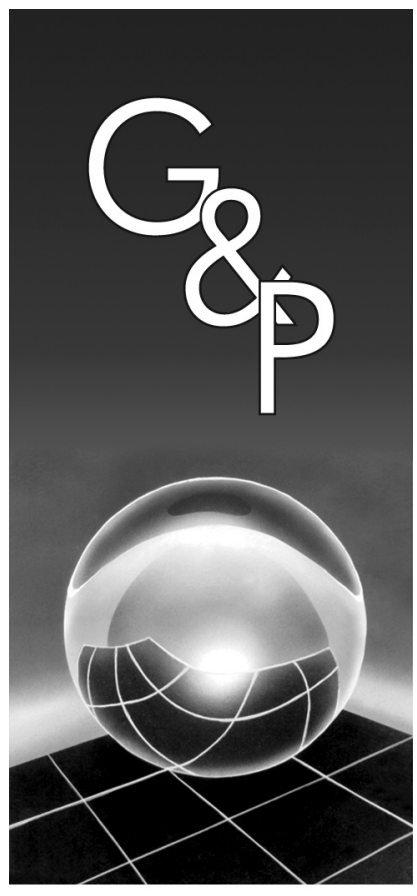

Loreni Teresinha Brandalise

Geysler Rogis Flor Bertolini

Cláudio Antonio Rojo

Álvaro Guilhermo Rojas Lezana

Osmar Possamai

\section{Resumo}

Objetivando descobrir se a percepção ambiental está associada ao grau de educação ambiental que a pessoa recebe, este artigo apresenta um estudo comparativo entre os universitários que possuem e os que não possuem na grade curricular de seus cursos uma disciplina relacionada às questões ambientais. $O$ instrumento utilizado foi adaptado do modelo VAPERCOM. O estudo contribui à medida que avalia o comportamento do consumidor considerando sua percepção em relação à variável ambiental, fornecendo subsídios à gestão organizacional no planejamento de ações de acordo com as expectativas e avaliação dos consumidores.

Palavras-chave: Educação ambiental. Comportamento. Percepção.

\section{Introdução}

A atual abordagem em relação ao meio ambiente considera que os recursos naturais são finitos e, alguns até escassos. Movimentos visando à diminuição dos impactos introduzidos pelas atividades industriais sobre o meio ambiente vêm ganhando força desde a década de 70 , requerendo normas para sistemas de gestão ambiental que norteiem as organizações. A conscientização da sociedade sobre a importância desse assunto proporcionou o surgimento de produtos e serviços 'ecológicos'.

O Relatório Ambiental da ONU também mostra que a humanidade está acordando para a urgência e importância da questão ambiental, unindo forças para participar da campanha global contra a mudança climática (LAVORATO, 2007). Os consumidores podem exercer pressão sobre uma empresa para que esta adote medidas ambientais responsáveis para não ser eliminada de sua lista de fornecimento.

Isso demonstra que é preciso desencadear um processo contínuo de sensibilização e conscientização dos consumidores individuais, o que pode ser conseguido com ações pró-ativas e divulgação delas por parte dos fabricantes. As escolas podem ser um instrumento de divulgação da educação ambiental.

O presente estudo tem por objetivo descobrir se a percepção ambiental está associada ao grau de educação ambiental que a pessoa possui. Desta forma, o estudo contribui à medida que avalia o comportamento dos universitários enquanto consumidores, a partir da sua percepção em relação à variável ambiental, considerando a Análise do Ciclo de Vida do produto - ACV.

As informações obtidas fornecem subsídios à gestão organizacional no planejamento de ações, considerando o posicionamento, as expectativas e avaliação deste nicho de consumidores.

\section{Modelo e procedimentos metodológicos}

O estudo tomou como base o modelo desenvolvido por Brandalise (2008) em sua tese de doutorado denominado Variável Ambiental; Percepção e Comportamento do Consumidor - VAPERCOM, o qual foi desenvolvido para avaliar a percepção do consumidor considerando a variável ambiental nas etapas da ACV, visando o incremento da competitividade organizacional.

O modelo foi concebido considerando três elementos que atuam sobre o consumidor no macro ambiente: a variável ambiental, os estímulos (internos e externos) e as influências (sociais, de marketing e situacionais) que incidem sobre outros três elementos associados ao produto 
e ao consumidor: a $\mathrm{ACV}$, a percepção e o processo de compra (Figura 1).

Os elementos que compõem o Ambiente (influenciadores) possuem uma interação com os elementos (influenciados) que compõem o Produto \& Consumidor. $\mathrm{Na}$ interação entre os elementos, a variável ambiental influencia a cadeia produtiva, considerando as principais etapas da $\mathrm{ACV}$, da extração da matéria-prima ao descarte; os estímulos internos e externos são interpretados e selecionados e conduzem à percepção; e as influências sociais, de marketing e situacionais incidem no processo de decisão de compra. A interação dos elementos pode ser visualizada na Figura 2, forma final do modelo VAPERCOM.
Conforme demonstra a espiral, de algum modo esses elementos interagem e se inter-relacionam, e isso se reflete no comportamento de compra e consumo, indicando o comportamento ambiental. Com base no comportamento ambiental, utilizando o conceito da ACV, o qual compreende os estágios do ciclo produtivo da extração da matéria-prima ao descarte do produto, pode o fabricante gerenciar melhor seus produtos definindo estratégias de ações características de agregação de valor de forma a promover a compra de seu produto e ainda contribuir para a preservação do meio ambiente.

O conjunto de conceitos do VAPERCOM elaborado na forma de modelo de gestão foi desenvolvido em quatro

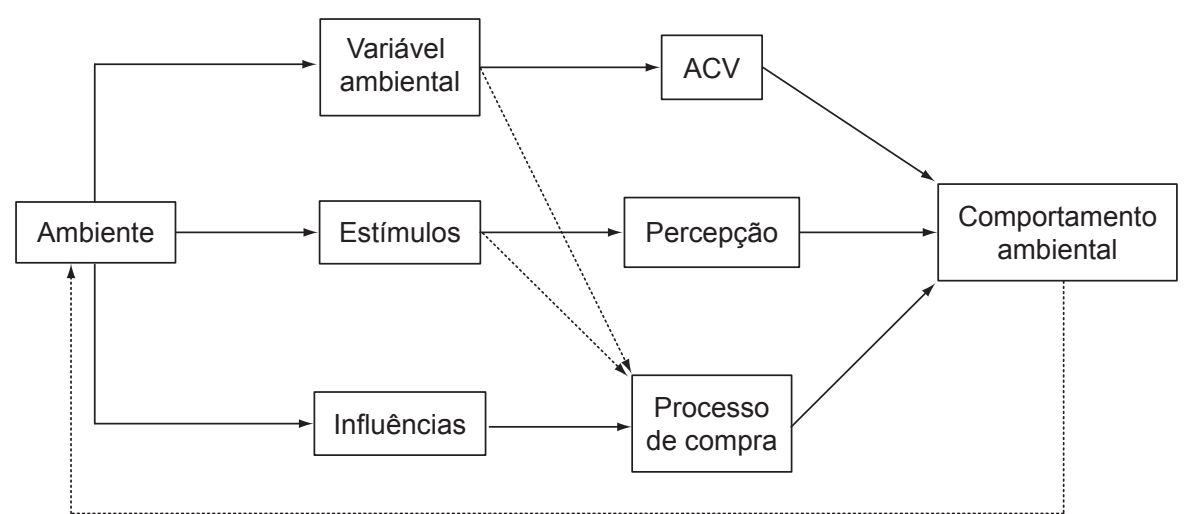

Figura 1. Concepção do VAPERCOM. Fonte: Brandalise (2008).

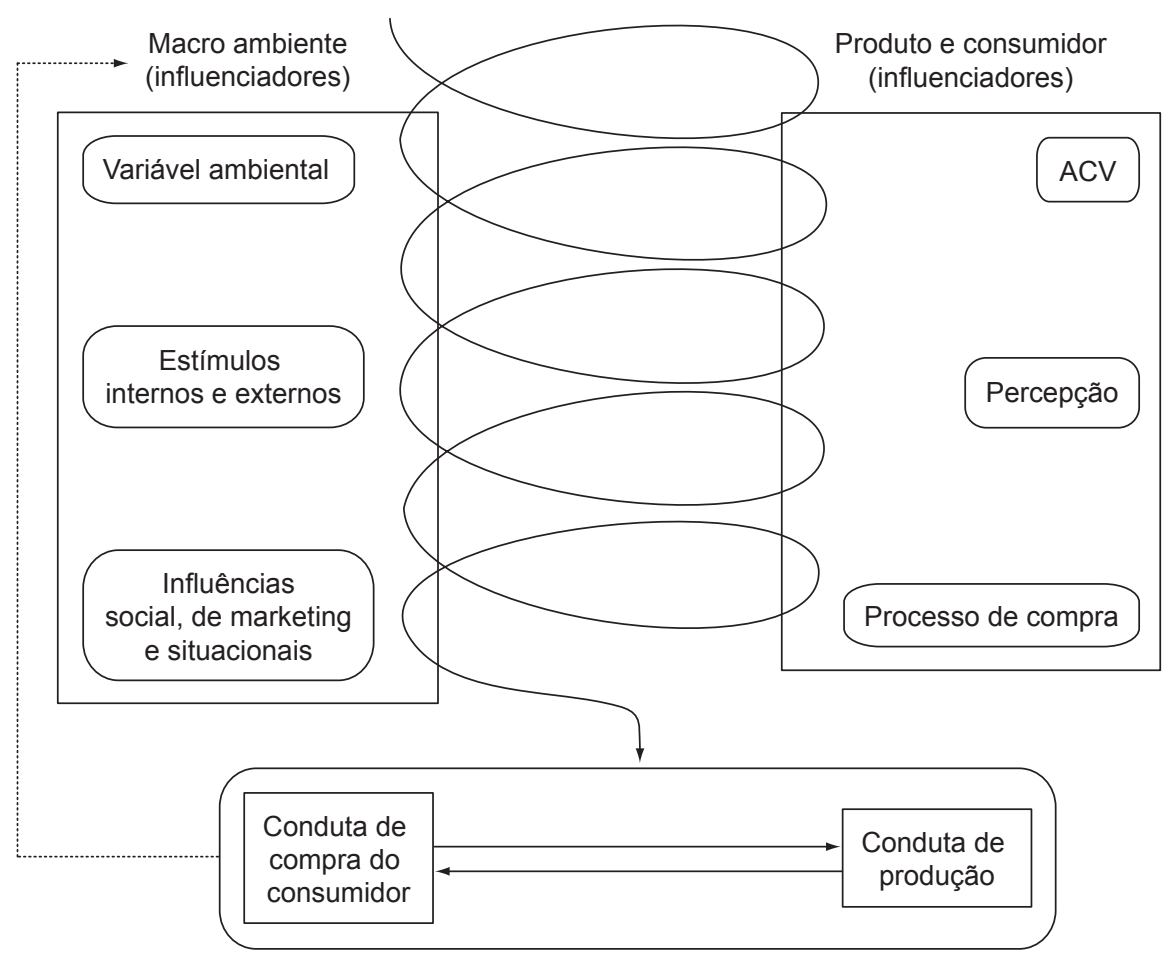

Figura 2. Modelo VAPERCOM. Fonte: Brandalise (2006). 
etapas, conforme detalhes no Quadro 1: (1) caracterização do produto e do potencial consumidor; (2) identificação do perfil do pesquisado, da percepção ambiental, do consumo ecológico e das etapas da ACV; (3) identificação das discrepâncias ( $\mathrm{gap}$ 's) entre as características ambientais do produto e aquelas que o consumidor percebe; e, por fim, (4) definição de oportunidades de ações (de incremento e/ou ajustes).

O conjunto de questões da Etapa 1 é formado por questões que visam identificar o perfil do pesquisado em relação ao sexo, idade, instrução, renda familiar e fonte de informações sobre as questões ambientais e a ACV. As características demográficas são importantes porque frequentemente definem se o consumidor pode e se deseja comprar.
O conjunto de questões da Etapa 2 - Percepção Ambiental é formado por questões que se referem às ações, à conduta ambiental no cotidiano, considerando os elementos redução/ conservação de recursos no consumo, reutilização e reciclabilidade, nos quais se busca verificar o grau de percepção e conduta do consumidor, considerando a variável ambiental.

As características psicográficas incluem as necessidades individuais, percepção, atitude, personalidade e estilo de vida e são importantes, pois são determinantes pessoais ou intrapessoais do comportamento do consumidor.

O conjunto de questões Consumo Ecológico é formado por questões referentes ao comportamento de compra e consumo, considerando os elementos: material renovável, consumo de energia (na utilização), vida útil do produto,

Quadro 1. Detalhamento das etapas do modelo VAPERCOM.

\begin{tabular}{|c|c|c|c|c|}
\hline Etapas & Objetivos & Atividades & Resultados esperados & Agentes \\
\hline $\begin{array}{l}\text { 1.Caracterização do } \\
\text { produto e do consumidor } \\
\text { 1.1 Caracterização do produto } \\
\begin{array}{l}1.2 \text { Caracterização do } \\
\text { potencial consumidor }\end{array}\end{array}$ & $\begin{array}{l}\text { 1.1 Caracterizar os } \\
\text { elementos ao longo } \\
\text { do ciclo de vida do produto } \\
\text { 1.2. Identificar grupos } \\
\text { homogêneos representativos } \\
\text { de certo segmento de } \\
\text { mercado, potenciais } \\
\text { consumidores do produto } \\
\text { em estudo }\end{array}$ & $\begin{array}{l}\text { 1.1 Definição do produto } \\
\text { (ou classe) da org. para o } \\
\text { estudo e caracterização na } \\
\text { ótica da redução, reutilização } \\
\text { e reciclabilidade ao } \\
\text { longo do ciclo de vida } \\
1.2 \text { Definição do número } \\
\text { amostral de potenciais } \\
\text { consumidores do produto }\end{array}$ & $\begin{array}{l}\text { 1.1 Produto } \\
\text { caracterizado. } \\
\text { 1.2 População e } \\
\text { amostra da pesquisa } \\
\text { definido }\end{array}$ & $\begin{array}{l}\text { O pesquisador } \\
\text { ou a } \\
\text { organização } \\
\text { interessada }\end{array}$ \\
\hline $\begin{array}{l}\text { 2. Identificação do perfil, } \\
\text { percepção ambiental, consumo } \\
\text { ecológico e preocupação nas } \\
\text { etapas da ACV } \\
\text { 2.1 Caracterização do perfil } \\
2.2 \text { Identificação da } \\
\text { percepção ambiental } \\
\begin{array}{l}2.3 \text { Identificação } \\
\text { do consumo ecológico }\end{array} \\
\begin{array}{l}\text { 2.4 Identificação da } \\
\text { preocupação nas } \\
\text { etapas da ACV }\end{array}\end{array}$ & $\begin{array}{l}\text { 2.1 Caracterizar o } \\
\text { pesquisado quanto ao perfil. } \\
\text { 2.2 Medir o grau de } \\
\text { percepção ambiental } \\
\text { 2.3 Identificar o } \\
\text { comportamento de } \\
\text { consumo considerando a } \\
\text { variável ambiental } \\
\text { 2.4 Identificar a } \\
\text { preocupação ambiental } \\
\text { do pesquisado nas } \\
\text { etapas da ACV }\end{array}$ & $\begin{array}{l}\text { Coleta dos dados por meio } \\
\text { da aplicação de instrumento } \\
\text { de pesquisa considerando } \\
\text { os elementos redução, } \\
\text { reutilização e reciclabilidade }\end{array}$ & $\begin{array}{l}\text { Perfil do pesquisado, } \\
\text { grau de percepção e } \\
\text { comportamento de } \\
\text { compra considerando } \\
\text { a variável ambiental ao } \\
\text { longo do ciclo de vida } \\
\text { conhecidos }\end{array}$ & $\begin{array}{l}\text { O pesquisador } \\
\text { ou a } \\
\text { organização }\end{array}$ \\
\hline $\begin{array}{l}\text { 3. Identificação das } \\
\text { discrepâncias (gap) } \\
\text { entre as características } \\
\text { ambientais do produto e } \\
\text { as que o consumidor percebe. }\end{array}$ & $\begin{array}{l}\text { Verificar as discrepâncias } \\
\text { das origens e das } \\
\text { características do produto e } \\
\text { as percebidas pelo usuário } \\
\text { em relação à ACV }\end{array}$ & $\begin{array}{l}\text { Mapeamento do produto e } \\
\text { a percepção do usuário em } \\
\text { relação à ACV }\end{array}$ & $\begin{array}{l}\text { Discrepâncias } \\
\text { (ou conformidade) } \\
\text { de características } \\
\text { identificadas }\end{array}$ & $\begin{array}{l}\text { O pesquisador } \\
\text { ou a } \\
\text { organização }\end{array}$ \\
\hline $\begin{array}{l}\text { 4. Identificação de } \\
\text { oportunidades de ações }\end{array}$ & $\begin{array}{l}\text { Identificar ações de } \\
\text { incremento/ajustes para } \\
\text { ganho de competitividade }\end{array}$ & $\begin{array}{l}\text { Definição das ações de } \\
\text { incremento ou ajustes } \\
\text { relativos ao produto ou de } \\
\text { ações que possam levar à } \\
\text { mudança de comportamento }\end{array}$ & $\begin{array}{l}\text { Ações de incremento } \\
\text { ou de ajustes para } \\
\text { efetivar o processo de } \\
\text { compra definidas }\end{array}$ & Organização \\
\hline
\end{tabular}

Fonte: Brandalise (2006). 
reutilização e reciclabilidade, objetivando classificar o comportamento de compra e consumo considerando a variável ambiental.

No Conjunto de questões Etapas da ACV, se questiona sobre a preocupação do respondente em relação à matéria prima, processo de produção, utilização, pós-utilização e descarte do produto, considerando os elementos redução, reutilização e reciclabilidade. O objetivo desse conjunto de questões é identificar o grau de percepção do consumidor em relação à variável ambiental no comportamento de compra e consumo em cada uma das etapas da ACV.

Após a aplicação do instrumento, os dados são tabulados utilizando o Quadro 2, no qual as questões são tabuladas multiplicando o número de vezes de cada resposta (a) pela respectiva pontuação a ela atribuída (b). Somam-se todos os resultados (c) e este é dividido pelo número de questões relacionadas à percepção ecológica (d).

Para viabilizar os cálculos de mensuração dos indicadores dos três conjuntos de questões, utilizam-se a Classificação do grau de percepção ambiental (Quadro 3), a Classificação do grau do comportamento de compra e consumo ecológico (Quadro 4) e a Classificação da preocupação do consumidor em relação à ACV (Quadro 5), respectivamente, definidas a partir das Escalas Likert, as quais requerem que o entrevistado indique seu grau de concordância ou discordância a declarações relativas ao que se quer medir.

Quadro 2. Alocação de pesos e elaboração do grau de percepção, de consumo ecológico e de preocupação em relação à ACV.

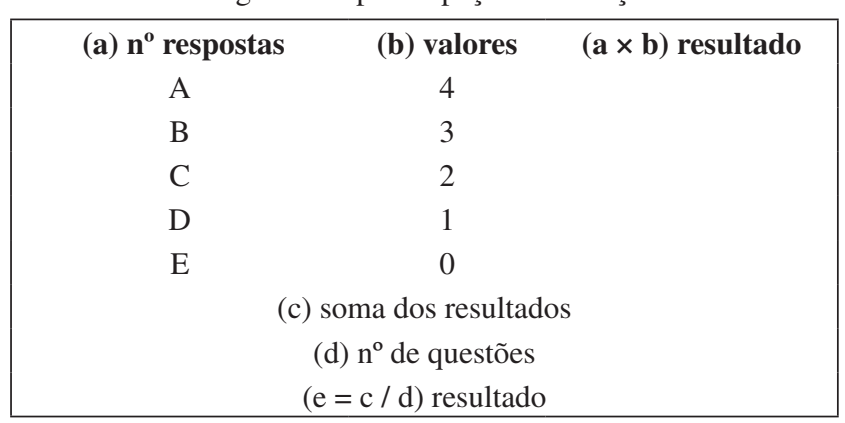

Fonte: adaptado de Bertolini (2004).

Quadro 3. Classificação do grau de percepção ambiental.

\begin{tabular}{|lc|}
\hline \multicolumn{1}{|c|}{ Grau de percepção em } \\
relação às questões ambientais & Valores \\
A) Possui alta percepção ecológica & Entre 3,3 e 4,0 \\
B) Possui percepção ecológica & Entre 2,5 e 3,2 \\
$\begin{array}{l}\text { C) Possui potenciais traços } \\
\text { de percepção ambiental }\end{array}$ & Entre 1,7 e 2,4 \\
D) Possui poucos traços & \\
de percepção ambiental & Entre 0,9 e 1,6 \\
E) Não possui percepção ecológica & Até 0,8 \\
\hline
\end{tabular}

Fonte: Brandalise (2008).
Os valores atribuídos às questões alternativas de respostas e as escalas de classificação obedecem a intervalos de 0,7 pontos e são coloridas para facilitar a visualização dos resultados de acordo com a pontuação: entre 3,3 e 4,0 verde; entre 2,5 e 3,2 azul; entre 1,7 e 2,4 amarelo; entre 0,9 e 1,6 laranja; e até 0,8 vermelho.

A análise das respostas apuradas com a aplicação do instrumento permite verificar se a população pesquisada percebe as características dos produtos considerados ecologicamente corretos. A percepção ambiental, decorrente da interpretação dos estímulos externos (informações) e internos (crenças, valores), somada às influências recebidas do meio externo se reflete nas atitudes e comportamento de aquisição e consumo.

Embora tenha sido concebido para comparar as características ambientais do produto e aquelas que o consumidor percebe e considera, neste estudo o modelo foi adaptado para comparar a percepção e o comportamento entre os universitários que tiveram em sua grade curricular da graduação uma disciplina relacionada às questões ambientais. Salienta-se que não se entrou no mérito do nível de profundidade tratado em cada disciplina dos diferentes cursos relacionados, pois certamente este varia de curso para curso.

A população foi constituída de universitários dos 15 cursos da Universidade Estadual do Oeste do Paraná Unioeste, campus Cascavel, matriculados no quarto ano,

Quadro 4. Classificação do comportamento de compra e consumo ecológico.

\begin{tabular}{|lc|}
\hline \multicolumn{1}{|c|}{ Grau de consumo de } & Valores \\
produtos ecologicamente corretos & \\
A) Consumidor ecológico & Entre 3,3 e 4,0 \\
B) Grande possibilidade de tornar-se & \\
um consumidor ecológico & Entre 2,5 e 3,2 \\
C) Potencial possibilidade de tornar-se & \\
um consumidor ecológico & Entre 1,7 e 2,4 \\
D) Fraca possibilidade de tornar-se & Entre 0,9 e 1,6 \\
um consumidor ecológico & Até 0,8 \\
\hline
\end{tabular}

Fonte: Brandalise (2008).

Quadro 5. Classificação da preocupação do consumidor em relação à $\mathrm{ACV}$.

\begin{tabular}{|cc|}
\hline $\begin{array}{c}\text { Grau de preocupação } \\
\text { em relação às etapas da ACV }\end{array}$ & Valores \\
A) Forte preocupação & Entre 3,3 e 4,0 \\
B) Frequente preocupação & Entre 2,5 e 3,2 \\
C) Mediana preocupação & Entre 1,7 e 2,4 \\
D) Fraca preocupação & Entre 0,9 e 1,6 \\
E) Nenhuma preocupação & Até 0,8 \\
\hline
\end{tabular}

Fonte: Brandalise (2008). 
totalizando 575 elementos. A pesquisa foi aplicada em outubro de 2006.

O critério de seleção da amostra foi a partir da lista completa dos elementos que formam a população. $\mathrm{O}$ parâmetro estimado para o nível de confiança foi $95 \%$, admitindo uma margem de erro máxima de $5 \%$ para mais ou para menos sobre o resultado total da amostra. O tamanho de amostra foi de 224 elementos, conforme recomenda Tagliacarne (1976), na 'Tabela para determinar a amplitude de uma amostra tirada de uma população finita'.

\section{Percepção, comportamento e educação ambiental - revisão teórica}

Para quantificar um fenômeno ambiental é necessário percebê-lo. Para o avanço do conhecimento científico, é essencial estudar os indicadores ambientais e trocar experiências (MAIA et al., 2001). A percepção é claramente mais do que o processo no qual os estímulos vencem os sentidos, é o início do processamento de informações, a interpretação dos estímulos aos quais se presta a atenção de acordo com a conformação mental existente, que são as atitudes, experiência e motivação (BAKER, 2005).

Percepção é a interpretação que uma pessoa faz de uma mensagem e esta pode ser diferente dependendo de quem a recebe, o que leva a crer que o nível de instrução e experiência influencia no modo como um estímulo é percebido e, consequentemente, nas atitudes e comportamento de consumo.

Conforme Bowditch e Buono (1992), para compreender como e por que as pessoas assumem e mantêm certas formas de comportamento, é necessário entender um dos principais determinantes, que se baseia nos conceitos de sensação e percepção. A sensação se refere ao estímulo físico dos sentidos: visão, audição, paladar, tato e olfato. O conhecimento dessas sensações ajuda a explicar os 'comos' e 'porquês' do comportamento, entretanto, é preciso compreender como um indivíduo reage a essas sensações e como as organiza.

Segundo Bennett e Kassarjian (1975) e Bowditch e Buono (1992), esse processo é chamado de percepção e se refere à maneira como as mensagens desses órgãos são interpretadas para dar ordem e significado ao nosso meio ambiente. Pessoas diferentes podem ver a mesma situação de modos diferentes, a interpretação do significado de certo evento determina como esses indivíduos reagirão. Nesse contexto, a percepção pode ser considerada uma variável interventora, que influencia o processo de tomada de decisão de compra.

Entretanto, apesar de intervir na tomada de decisão, a percepção é decorrente da educação ambiental que os consumidores possuem. A educação ambiental é um dos instrumentos de que se dispõe para tentar sanar ou minimizar os problemas ambientais, pois, conforme uma das definições de Meadows et al. (1972), educação ambiental é o aprendizado para compreender, apreciar, saber lidar e manter os sistemas ambientais na sua totalidade. Portanto, a educação ambiental deve buscar valores que conduzam a uma convivência harmoniosa com o ambiente e as demais espécies que habitam o planeta.

Supõe-se que para perceber é necessário ser consciente de que as ações do homem influenciarão no futuro da natureza e do planeta. A partir do conhecimento e da percepção ambiental, as atitudes, o comportamento poderão ser modificados. É possível racionalizar o uso dos recursos naturais no nosso cotidiano com a mudança de hábitos.

A percepção que os consumidores têm sobre o papel das empresas na sociedade é cada vez mais importante, o que pode ser observado nos resultados da pesquisa realizada pelo Instituto Akatu et al. (2004), os quais permitem compreender até que ponto a percepção do consumidor influencia na postura das empresas. A pesquisa revela que empresas que divulgam relatório social e ambiental são avaliadas positivamente e estimulam o consumo de seus produtos. Dessa forma, as pessoas podem interferir na atuação das empresas consumindo ou não seus produtos.

O estudo do comportamento do consumidor focaliza o quanto os estímulos ambientais, de marketing e outros influenciam as decisões de compra do consumidor. $\mathrm{O}$ consumo é amplamente influenciado pela idade, renda, nível de educação, padrão de mobilidade e gosto dos consumidores. Entender o comportamento do consumidor envolve estudos que busca agrupá-los em segmentos homogêneos de consumo (KOTLER, 2000). Essa mudança ocorre de várias maneiras, a partir de influências pessoais e do meio.

O marketing pode influenciar a probabilidade de ativação de necessidade de compra com propagandas e inovações de produto, afirmam Engel et al. (2000), e, algumas vezes, é suficiente simplesmente lembrar aos consumidores de uma necessidade. A influência varia de acordo com as características do consumidor, as quais afetam sua percepção.

A pesquisa em percepção ambiental é um importante elemento para o planejamento do ambiente, já que uma das dificuldades para a proteção dos ambientes naturais está na existência de diferenças de percepções dos valores, da importância deles entre os indivíduos de culturas diferentes ou de grupos sócio-econômicos que desempenham funções distintas no plano social, nesses ambientes (UNESCO, 1973).

Para tentar sanar ou minimizar os problemas ambientais, a educação ambiental pode ser utilizada, pois é o aprendizado para compreender, apreciar, saber lidar e manter os sistemas ambientais na sua totalidade (MEADOWS et al., 1972).

No entanto, a educação ambiental concorre com os apelos ao consumo veiculados pelos meios de comunicação de massa nos quais prevalece o apelo ao consumismo, embora 
também veiculem campanhas ambientalistas. Por essa razão, é necessário conhecer como o estudante se posiciona enquanto consumidor diante dos diferentes discursos e o que leva em consideração ao escolher determinado produto ou marca.

Serrano (2003) infere que as escolas não estão conseguindo concretizar as expectativas a fim de propiciar uma mudança de valores e atitudes, adequando-os ao consumerismo ambiental. Os alunos, em geral, não se comprometem com os objetivos comportamentais da educação ambiental, o que resulta em um consumo de produtos ambientalmente incorretos, comprovando a existência de um descompasso entre teoria e prática.

Brandalise (2008) sugere o uso de ferramentas de educação ambiental nas políticas públicas para orientar as escolas brasileiras, convergindo na qualidade do processo de desenvolvimento, na perspectiva do desenvolvimento sustentável, razão pela qual uma série de sistemas de indicadores vem sendo construída buscando mensurar o grau de sustentabilidade. Os fatores de pesquisa em voga são os de desenvolvimento sustentável apontando para as variáveis ambientais, sociais e econômicas.

Nesse sentido, a educação ambiental deve estar comprometida com uma abordagem da problemática ambiental que interrelacione os aspectos sociais, ecológicos, econômicos, políticos, culturais, científicos, tecnológicos e éticos. É difícil e complexo compreender com clareza os limites e as possibilidades da educação ambiental. Desse modo, a autora recomenda o desenvolvimento de projetos simples e objetivos, ajustados à vivência do cotidiano casa/ escola/comunidade por meio da interdisciplinaridade.

\section{Resultados e discussão}

A primeira etapa do modelo, caracterização do pesquisado, objetiva identificar o perfil do pesquisado em relação ao sexo, idade, instrução, renda familiar e fonte de informações sobre as questões ambientais. Os dados relativos a esta etapa não são apresentados, pois, na realização da análise e cruzamento dos resultados, estes não se mostraram significativos diante da problemática na qual repousa este estudo.

Dos 15 cursos de graduação, somente 6 incluem em sua grade curricular uma disciplina relacionada às questões ambientais (são eles: Administração, Ciências Biológicas, Farmácia, Engenharia Agrícola, Fisioterapia e Enfermagem). Assim, a amostra (224) foi dividida entre aqueles que tiveram uma disciplina relacionada às questões ambientais Com QA $=94-$ e aqueles pertencentes aos 9 cursos que não tiveram uma disciplina relacionada às questões ambientais - Sem QA = 130 (são eles: Ciências Contábeis, Ciências Econômicas, Engenharia Civil, Informática, Letras, Matemática, Medicina, Odontologia e Pedagogia).
Questionados sobre a principal fonte de obtenção de informações sobre as questões ambientais, as respostas apontam que a maioria (Com QA 78\% e Sem QA 84\%) obtém informações por meio da mídia, seja televisão, rádio, jornais, revistas e outros meios de comunicação. As outras fontes de informações sobre as questões ambientais receberam a seguinte pontuação, conforme mostra a Figura 3: escola (Com QA $=15 \%$ e Sem QA $=4 \%$ ); rótulos e embalagem dos produtos (Com $\mathrm{QA}=3 \%$ e Sem $\mathrm{QA}=7 \%)$; amigos $(\mathrm{Com} \mathrm{QA}=3 \%$ e Sem $\mathrm{QA}=4 \%)$; família (Com QA $=1 \%$ e Sem $\mathrm{QA}=4,2 \%$ ).

Destaca-se que a mídia é a principal fonte de informações mesmo para aqueles que têm uma disciplina relacionada às questões ambientais na grade curricular de seus cursos.

A segunda etapa do modelo - Percepção Ambiental é formada por questões que se referem às ações, à conduta ambiental no cotidiano, considerando os elementos redução/ conservação de recursos no consumo, reutilização e reciclabilidade, e se busca verificar o grau de percepção e conduta do consumidor, considerando a variável ambiental.

As características psicográficas incluem as necessidades individuais, percepção, atitude, personalidade e estilo de vida e são importantes, pois são determinantes pessoais ou intrapessoais do comportamento do consumidor. A percepção ambiental é demonstrada pela ação ou comportamento em relação às atividades domésticas, profissionais e de lazer, sobretudo na aquisição e consumo de produtos considerados ecologicamente corretos.

Considera-se produto ecologicamente correto aquele que impacta minimamente o meio ambiente, nas principais etapas do ciclo de vida: aquisição e processamento de matérias-primas, utilização, pós-utilização e descarte, considerando a extração de matéria-prima, transporte, consumo de energia, vida útil, biodegradabilidade e reciclabilidade. As Tabelas 1 e 2 mostram a frequência de respostas das questões da população Com QA e Sem QA, respectivamente.

A análise da pontuação obtida nesse conjunto de questões apresenta as médias e o tratamento estatístico da pontuação apresentada nas Tabelas 1 e 2, Percepção Ambiental Com QA

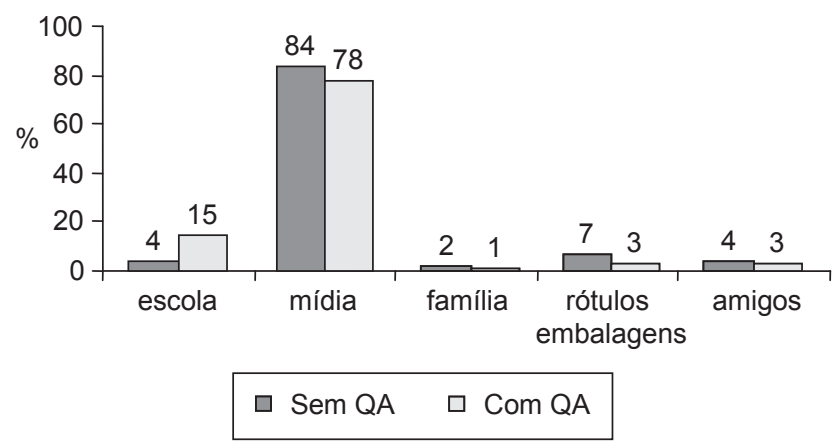

Figura 3. Fonte de obtenção de informações sobre as questões ambientais. Fonte: Pesquisa aplicada (2006). 
e Sem QA, efetuados de acordo com a Tabela 3 - Alocação de pesos e elaboração do grau de percepção ambiental, adaptada do modelo de Bertolini e Possamai (2005).

Os respectivos valores atribuídos às alternativas de respostas foram: A (sempre) $=4$ pontos; $\mathrm{B}$ $($ frequentemente $)=3$ pontos $; \mathrm{C}$ (algumas vezes $)=2$ pontos; $\mathrm{D}($ pouquíssimas vezes $)=1$ ponto; $\mathrm{E}($ nunca $)=0$.

Pelo valor obtido com a alocação de pesos 2,79 e 2,8, respectivamente, e de acordo com a Classificação do grau de percepção ambiental da amostra Com e Sem QA, apresentada na Tabela 4, os dois grupos 'possuem percepção ecológica'. Pela diferença mínima encontrada, pode-se concluir que as duas amostras possuem percepção muito semelhante e que, o fato de haver uma disciplina relacionada às questões ambientais (Com QA) ou não (Sem QA), não faz diferença.
A análise das respostas apuradas com a aplicação do instrumento, em relação à Percepção Ambiental, permitiu verificar que ambas as amostras da população pesquisada percebem as características dos produtos considerados ecologicamente corretos.

Observa-se discreta diferença entre a amostra que têm uma disciplina relacionada às questões ambientais (com QA) em sua grade curricular e a que não tem (sem QA). Isso se justifica pelas respostas do primeiro conjunto de questões, nas quais a maioria absoluta afirma ser a mídia a principal fonte de informações sobre as questões ambientais.

Verifica-se, pelos resultados, que, embora os estudantes tenham uma disciplina que trata das questões ambientais, não há efetividade no seu comportamento enquanto consumidores.

O processo de compra de produtos pelos consumidores passa pela tomada de decisão, quando as informações

Tabela 1. Frequência de respostas do conjunto percepção ambiental com QA .

\begin{tabular}{|c|c|c|c|c|c|}
\hline Conjunto 02 - percepção ambiental - com QA & Sempre & Frequentemente & Algumas vezes & Pouquíssimas vezes & Nunca \\
\hline $\begin{array}{l}\text { Antes de jogar algo no lixo, você } \\
\text { pensa em como poderia reutilizá-lo? }\end{array}$ & 8 & 20 & 35 & 23 & 8 \\
\hline Você é adepto da reciclagem? & 31 & 25 & 19 & 10 & 9 \\
\hline $\begin{array}{l}\text { Você separa o lixo que pode ser } \\
\text { reciclado e o dispõe para coleta? }\end{array}$ & 19 & 20 & 12 & 17 & 26 \\
\hline $\begin{array}{l}\text { Apaga as luzes, desliga TV e outros } \\
\text { aparelhos quando sai do ambiente? }\end{array}$ & 52 & 24 & 12 & 5 & 0 \\
\hline $\begin{array}{l}\text { Procura não deixar a torneira aberta ao } \\
\text { escovar os dentes ou ao fazer a barba? }\end{array}$ & 59 & 20 & 10 & 2 & 4 \\
\hline $\begin{array}{l}\text { Você utiliza os dois lados dos papéis, } \\
\text { ou reutiliza rascunhos? }\end{array}$ & 47 & 26 & 17 & 2 & 1 \\
\hline Você evita imprimir coisas desnecessárias? & 43 & 30 & 17 & 3 & 2 \\
\hline Total & 259 & 165 & 122 & 62 & 50 \\
\hline
\end{tabular}

Fonte: Pesquisa aplicada (2006).

Tabela 2. Frequência de respostas do conjunto percepção ambiental sem QA.

\begin{tabular}{|c|c|c|c|c|c|}
\hline Conjunto 02 - percepção ambiental - sem QA & Sempre & Frequentemente & Algumas vezes & Pouquíssimas vezes & Nunca \\
\hline $\begin{array}{l}\text { Antes de jogar algo no lixo, você } \\
\text { pensa em como poderia reutilizá-lo? }\end{array}$ & 15 & 26 & 43 & 33 & 13 \\
\hline Você é adepto da reciclagem? & 52 & 30 & 30 & 12 & 6 \\
\hline $\begin{array}{l}\text { Você separa o lixo que pode ser } \\
\text { reciclado e o dispõe para coleta? }\end{array}$ & 25 & 21 & 21 & 31 & 32 \\
\hline $\begin{array}{l}\text { Apaga as luzes, desliga TV e outros } \\
\text { aparelhos quando sai do ambiente? }\end{array}$ & 76 & 43 & 7 & 3 & 1 \\
\hline $\begin{array}{l}\text { Procura não deixar a torneira aberta ao } \\
\text { escovar os dentes ou ao fazer a barba? }\end{array}$ & 78 & 32 & 10 & 1 & 8 \\
\hline $\begin{array}{l}\text { Você utiliza os dois lados dos papéis, } \\
\text { ou reutiliza rascunhos? }\end{array}$ & 57 & 43 & 21 & 6 & 3 \\
\hline Você evita imprimir coisas desnecessárias? & 64 & 31 & 30 & 3 & 1 \\
\hline Total & 367 & 226 & 162 & 89 & 64 \\
\hline
\end{tabular}

Fonte: Pesquisa aplicada (2006). 
Tabela 3. Alocação de pesos e elaboração do grau de percepção, consumo ambiental e preocupação nas etapas da ACV da população com e sem QA.

\begin{tabular}{|c|c|c|c|c|c|}
\hline \multicolumn{3}{|c|}{ Com QA } & \multicolumn{3}{|c|}{ Sem QA } \\
\hline (a) $n^{0}$ respostas & (b) valores & $(\mathbf{a} \times \mathbf{b})$ resultado & (a) $\mathrm{n}^{0}$ respostas & (b) valores & $(\mathbf{a} \times \mathbf{b})$ resultado \\
\hline$a=259$ & 4 & 1036 & $a=367$ & 4 & 1468 \\
\hline$b=165$ & 3 & 495 & $b=226$ & 3 & 678 \\
\hline$c=122$ & 2 & 244 & $c=162$ & 2 & 324 \\
\hline$d=62$ & 1 & 62 & $\mathrm{~d}=87$ & 1 & 87 \\
\hline $\mathrm{e}=50$ & 0 & 0 & $e=64$ & 0 & 0 \\
\hline \multicolumn{2}{|c|}{ (c) soma dos resultados } & 1837 & \multicolumn{2}{|c|}{ (c) soma dos resultados } & 2557 \\
\hline \multicolumn{2}{|c|}{ (d) $n^{\circ}$. de questões } & 658 & \multicolumn{2}{|c|}{ (d) $\mathrm{n}^{\mathrm{o}}$. de questões } & 910 \\
\hline \multicolumn{2}{|c|}{$(\mathrm{e}=\mathrm{c} / \mathrm{d})$ resultado } & 2,79 & \multicolumn{2}{|c|}{$(\mathrm{e}=\mathrm{c} / \mathrm{d})$ resultado } & 2,8 \\
\hline
\end{tabular}

Fonte: Pesquisa aplicada (2006).

Tabela 4. Classificação do grau de percepção ambiental.

\begin{tabular}{lc}
\hline \multicolumn{1}{c}{$\begin{array}{c}\text { Grau de percepção em } \\
\text { relação às questões ambientais }\end{array}$} & Valores \\
\hline A) Possui alta percepção ambiental & Entre 3,3 e 4,0 \\
B) Possui percepção ambiental & Entre 2,5 e 3,2 \\
$\begin{array}{l}\text { C) Possui potenciais traços de percepção } \\
\text { ambiental }\end{array}$ & Entre 1,7 e 2,4 \\
$\begin{array}{l}\text { D) Possui poucos traços de percepção } \\
\text { ambiental }\end{array}$ & Entre 0,9 e 1,6 \\
E) Não possui percepção ecológica. & Até 0,8 \\
\hline
\end{tabular}

Fonte: Pesquisa aplicada (2006).

'percebidas' pelas pessoas são usadas para avaliar e escolher dentre as possíveis alternativas. Independentemente do tipo de tomada de decisão dos consumidores, as compras feitas por eles auxiliam a tomada de decisão em relação à oferta de novos produtos no mercado.

Assim, como a percepção ambiental, conhecer o grau do consumo ecológico é importante, já que o comportamento de consumo indica o grau de percepção refletido nas ações de aquisição e consumo.

O conjunto Consumo Ecológico, apresentado nas Tabelas 5 e 6 , é formado por onze questões referentes ao comportamento de compra e consumo, considerando os elementos: material renovável, consumo de energia (na utilização), vida útil do produto, reutilização e reciclabilidade, objetivando classificar o comportamento de compra e consumo considerando a variável ambiental.

Para a análise da pontuação nesse conjunto de questões foi utilizada novamente a Tabela 3. Pelo valor obtido com a alocação de pesos aplicado às amostras Com e Sem QA, 1,7 e 1,8, respectivamente, e de acordo com a classificação do grau de consumo de produtos ecologicamente corretos apresentada na Tabela 7, os integrantes dos dois grupos têm 'potencial possibilidade de tornar-se um consumidor ecológico'.
Observa-se no conjunto Consumo Ecológico discreta diferença entre a amostra que tem uma disciplina relacionada às questões ambientais (com QA) em sua grade curricular e a que não tem (sem QA). Isso também se justifica pelas respostas do primeiro conjunto de questões, nas quais a maioria absoluta afirma ser a mídia a principal fonte de informações sobre as questões ambientais.

As expectativas dos consumidores são úteis na tomada de decisão organizacional, no sentido de manter ou lançar novos produtos no mercado, pois identifica oportunidades de ações para estimular o consumo de certo produto, por meio de informações que permitem conhecer o comportamento de potenciais consumidores (BRANDALISE, 2008).

No Conjunto 04 - Etapas da ACV, questiona-se sobre a preocupação do respondente em relação à matéria-prima (origem dos recursos), processo de produção (resíduos gerados, consumo de energia), utilização (consumo de energia), pós-utilização (possibilidade de reutilização, reciclabilidade) e descarte (volume, biodegradabilidade, periculosidade) do produto, considerando os elementos redução, reutilização e reciclabilidade.

O objetivo desse conjunto de questões é identificar o grau de percepção do consumidor em relação à variável ambiental no comportamento de compra e consumo em cada uma das etapas da ACV. O resultado é apresentado nas Tabelas 8 e 9.

Para a análise da pontuação obtida nesses conjuntos de questões foi utilizada novamente a Tabela 3. Os valores atribuídos às alternativas de respostas foram: A (forte preocupação) $=4$ pontos; $\mathrm{B}$ (frequentemente me preocupo $)=3$ pontos; $\mathrm{C}$ (média preocupação $)=2$ pontos; $\mathrm{D}$ (fraca preocupação) $=1$ ponto; $\mathrm{E}$ (nenhuma preocupação) $=0$.

O valor obtido na tabulação, conforme a Tabela 2, a alocação de pesos aplicada às amostras Com QA resultou em 2,7 e Sem QA, 2,8. De acordo com a Classificação do grau de preocupação em relação às etapas da $\mathrm{ACV}$, 
Tabela 5. Frequência de respostas do conjunto consumo ecológico com QA.

\begin{tabular}{|c|c|c|c|c|c|}
\hline Conjunto 03 - consumo ecológico - com QA & Sempre & Frequentemente & $\begin{array}{l}\text { Algumas } \\
\text { vezes }\end{array}$ & $\begin{array}{l}\text { Pouquíssimas } \\
\text { vezes }\end{array}$ & Nunca \\
\hline $\begin{array}{l}\text { Você considera a variável ambiental } \\
\text { quando da compra de um produto? }\end{array}$ & 1 & 12 & 40 & 22 & 19 \\
\hline $\begin{array}{l}\text { Ao comprar você se deixar influenciar pela propaganda, pelos } \\
\text { amigos ou pela família em relação às questões ambientais? }\end{array}$ & 2 & 19 & 35 & 24 & 14 \\
\hline $\begin{array}{l}\text { Ao comprar, você procura saber se o } \\
\text { fabricante pratica ações ambientais? }\end{array}$ & 1 & 9 & 19 & 31 & 34 \\
\hline $\begin{array}{l}\text { Ao comprar, você valoriza o fabricante } \\
\text { que tem 'postura' ecologicamente correta? }\end{array}$ & 11 & 22 & 22 & 22 & 17 \\
\hline $\begin{array}{l}\text { Antes da compra você verifica rótulos e embalagens, para } \\
\text { identificar um 'produto' ecologicamente correto? }\end{array}$ & 1 & 11 & 21 & 31 & 30 \\
\hline $\begin{array}{l}\text { Procura comprar produtos e/ou embalagens fabricados com } \\
\text { material reciclado ou que têm potencial para serem reciclados? }\end{array}$ & 4 & 13 & 30 & 28 & 19 \\
\hline $\begin{array}{l}\text { Você verifica o consumo de energia } \\
\text { quando da compra de um produto? }\end{array}$ & 31 & 13 & 19 & 13 & 18 \\
\hline Você compra produtos biodegradáveis? & 4 & 20 & 40 & 22 & 8 \\
\hline $\begin{array}{l}\text { Você se dispõe a pagar mais por um } \\
\text { produto ecologicamente correto? }\end{array}$ & 9 & 6 & 31 & 28 & 20 \\
\hline $\begin{array}{l}\text { Você se dispõe a mudar de marca de produto } \\
\text { p/ auxiliar na conservação ambiental? }\end{array}$ & 18 & 17 & 35 & 20 & 4 \\
\hline $\begin{array}{l}\text { Você pagaria mais por caderno fabricado com } \\
\text { papel reciclado ou proveniente de árvore reflorestada? }\end{array}$ & 18 & 13 & 28 & 17 & 18 \\
\hline Total & 100 & 155 & 320 & 258 & 201 \\
\hline
\end{tabular}

Fonte: Pesquisa aplicada (2006).

Tabela 6. Frequência de respostas do conjunto consumo ecológico sem QA.

\begin{tabular}{|c|c|c|c|c|c|}
\hline Conjunto 03 - consumo ecológico - sem QA & Sempre & Frequentemente & $\begin{array}{c}\text { Algumas } \\
\text { vezes }\end{array}$ & $\begin{array}{c}\text { Pouquíssimas } \\
\text { vezes }\end{array}$ & Nunca \\
\hline $\begin{array}{l}\text { Você considera a variável ambiental } \\
\text { quando da compra de um produto? }\end{array}$ & 4 & 14 & 51 & 38 & 23 \\
\hline $\begin{array}{l}\text { Ao comprar você se deixar influenciar pela propaganda, pelos } \\
\text { amigos ou pela família em relação às questões ambientais? }\end{array}$ & 5 & 26 & 51 & 34 & 14 \\
\hline $\begin{array}{l}\text { Ao comprar, você procura saber se o } \\
\text { fabricante pratica ações ambientais? }\end{array}$ & 1 & 6 & 27 & 47 & 49 \\
\hline $\begin{array}{l}\text { Ao comprar, você valoriza o fabricante } \\
\text { que tem 'postura' ecologicamente correta? }\end{array}$ & 16 & 18 & 35 & 44 & 17 \\
\hline $\begin{array}{l}\text { Antes da compra você verifica rótulos e embalagens, para } \\
\text { identificar um 'produto' ecologicamente correto? }\end{array}$ & 1 & 13 & 43 & 41 & 32 \\
\hline $\begin{array}{l}\text { Procura comprar produtos e/ou embalagens fabricados com } \\
\text { material reciclado ou que têm potencial para serem reciclados? }\end{array}$ & 6 & 19 & 43 & 43 & 19 \\
\hline $\begin{array}{l}\text { Você verifica o consumo de energia } \\
\text { quando da compra de um produto? }\end{array}$ & 40 & 40 & 25 & 10 & 15 \\
\hline Você compra produtos biodegradáveis? & 9 & 38 & 59 & 19 & 5 \\
\hline $\begin{array}{l}\text { Você se dispõe a pagar mais por um } \\
\text { produto ecologicamente correto? }\end{array}$ & 5 & 13 & 60 & 31 & 21 \\
\hline $\begin{array}{l}\text { Você se dispõe a mudar de marca de } \\
\text { produto p/ auxiliar na conservação ambiental? }\end{array}$ & 24 & 37 & 46 & 19 & 4 \\
\hline $\begin{array}{l}\text { Você pagaria mais por caderno fabricado com } \\
\text { papel reciclado ou proveniente de árvore reflorestada? }\end{array}$ & 21 & 20 & 40 & 28 & 21 \\
\hline Total & 132 & 244 & 480 & 354 & 220 \\
\hline
\end{tabular}

Fonte: Pesquisa aplicada (2006). 
apresentada na Tabela 10, os dois grupos têm 'frequente preocupação' em relação às etapas da ACV.

Ao analisar cada etapa da ACV, observa-se que, nas etapas 'utilização do produto' e 'descarte', ambos os grupos

Tabela 7. Classificação do grau de consumo ecológico.

\begin{tabular}{lc}
\hline $\begin{array}{c}\text { Grau de consumo de produtos } \\
\text { ecologicamente corretos }\end{array}$ & Valores \\
\hline $\begin{array}{l}\text { A) Consumidor ecológico } \\
\text { B) Grande possibilidade de tornar-se }\end{array}$ & Entre 3,3 e 4,0 \\
um consumidor ecológico & Entre 2,5 e 3,2 \\
C) Potencial possibilidade de tornar-se & \\
um consumidor ecológico & Entre 1,7 e 2,4 \\
D) Fraca possibilidade de tornar-se um & \\
consumidor ecológico & Entre 0,9 e 1,6 \\
E) Não é um consumidor ecológico & Até 0,8 \\
\hline
\end{tabular}

Fonte: Pesquisa aplicada (2006). demonstraram 'forte preocupação', o que demonstra que não basta a inclusão da educação ambiental nas escolas, é preciso informar o consumidor para que as mudanças de comportamento se estabeleçam.

\section{Conclusão}

O estudo demonstrou a utilidade da ferramenta utilizada, ao apontar elementos que identificam os aspectos ambientais considerados no processo de decisão de compra do consumidor e a preocupação nas etapas da ACV.

Os resultados da pesquisa apontaram equilíbrio nos aspectos avaliados, seja sobre o grau de percepção, seja sobre o grau de consumo ecológico, seja pela preocupação nas etapas da $\mathrm{ACV}$, tanto aqueles que têm em seu currículo uma disciplina relacionada às questões ambientais como aqueles que não têm.

Tabela 8. Frequência de respostas do conjunto consumo ecológico com QA.

\begin{tabular}{|c|c|c|c|c|c|}
\hline Conjunto 04 - etapas da ACV - com QA & $\begin{array}{c}\text { Forte } \\
\text { preocupação }\end{array}$ & $\begin{array}{c}\text { Frequentemente } \\
\text { me preocupo }\end{array}$ & $\begin{array}{c}\text { Média } \\
\text { preocupação }\end{array}$ & $\begin{array}{c}\text { Fraca } \\
\text { preocupação }\end{array}$ & $\begin{array}{c}\text { Nenhuma } \\
\text { preocupação }\end{array}$ \\
\hline \multicolumn{6}{|c|}{ Em relação à matéria-prima indique o grau de preocupação com: } \\
\hline Origem dos recursos (se são renováveis) & 18 & 24 & 34 & 14 & 3 \\
\hline Impacto ambiental na extração (e no transporte) & 24 & 35 & 21 & 12 & 1 \\
\hline Total Parcial & 42 & 59 & 55 & 26 & 4 \\
\hline \multicolumn{6}{|c|}{ Em relação ao processo de produção indique o grau de preocupação com: } \\
\hline Consumo de energia (na produção) & 30 & 25 & 19 & 10 & 9 \\
\hline $\begin{array}{l}\text { Geração de resíduos sólidos, efluentes líquidos e } \\
\text { emissões atmosféricas }\end{array}$ & 36 & 30 & 19 & 5 & 3 \\
\hline $\begin{array}{l}\text { Consumo de combustível na armazenagem e/ou } \\
\text { transporte e distribuição }\end{array}$ & 26 & 25 & 24 & 10 & 7 \\
\hline Total Parcial & 92 & 80 & 62 & 25 & 19 \\
\hline \multicolumn{6}{|c|}{ Em relação à utilização do produto indique o grau de preocupação com: } \\
\hline Vida útil do produto & 42 & 28 & 18 & 3 & 2 \\
\hline Necessidade de energia & 28 & 33 & 24 & 7 & 1 \\
\hline Potencial contaminação do meio ambiente & 33 & 30 & 22 & 6 & 2 \\
\hline Embalagem (tipo e/ou volume) & 16 & 30 & 32 & 11 & 3 \\
\hline Total Parcial & 119 & 121 & 96 & 27 & 13 \\
\hline \multicolumn{6}{|c|}{ Em relação à pós-utilização do produto indique o grau de preocupação com: } \\
\hline Possibilidade de reutilização & 26 & 24 & 30 & 11 & 2 \\
\hline $\begin{array}{l}\text { Potencialidade de reaproveitamento de } \\
\text { componentes }\end{array}$ & 18 & 28 & 31 & 12 & 4 \\
\hline Possibilidade de reciclagem & 27 & 28 & 24 & 11 & 3 \\
\hline Total Parcial & 71 & 80 & 85 & 34 & 9 \\
\hline \multicolumn{6}{|c|}{ Em relação ao descarte do produto indique o grau de preocupação com: } \\
\hline Periculosidade ou toxidade & 53 & 25 & 11 & 3 & 1 \\
\hline Volume de material (incluindo embalagem) & 21 & 37 & 22 & 8 & 5 \\
\hline Biodegradabilidade & 22 & 29 & 27 & 11 & 4 \\
\hline Total Parcial & 96 & 91 & 60 & 22 & 10 \\
\hline Total geral & 420 & 431 & 358 & 134 & 56 \\
\hline
\end{tabular}

Fonte: Pesquisa aplicada (2006). 
Tabela 9. Frequência de respostas do conjunto consumo ecológico com QA.

\begin{tabular}{|c|c|c|c|c|c|}
\hline Conjunto 04 - etapas da ACV - sem QA & $\begin{array}{c}\text { Forte } \\
\text { preocupação }\end{array}$ & $\begin{array}{c}\text { Frequentemente } \\
\text { me preocupo }\end{array}$ & $\begin{array}{c}\text { Média } \\
\text { preocupação }\end{array}$ & $\begin{array}{c}\text { Fraca } \\
\text { preocupação }\end{array}$ & $\begin{array}{c}\text { Nenhuma } \\
\text { preocupação }\end{array}$ \\
\hline \multicolumn{6}{|c|}{ Em relação à matéria-prima indique o grau de preocupação com: } \\
\hline Origem dos recursos (se são renováveis) & 27 & 43 & 35 & 19 & 6 \\
\hline Impacto ambiental na extração (e no transporte) & 33 & 52 & 24 & 15 & 6 \\
\hline Total Parcial & 60 & 95 & 59 & 34 & 12 \\
\hline \multicolumn{6}{|c|}{ Em relação ao processo de produção indique o grau de preocupação com: } \\
\hline Consumo de energia (na produção) & 32 & 31 & 33 & 23 & 11 \\
\hline $\begin{array}{l}\text { Geração de resíduos sólidos, efluentes } \\
\text { líquidos e emissões atmosféricas }\end{array}$ & 47 & 41 & 24 & 14 & 4 \\
\hline $\begin{array}{l}\text { Consumo de combustível na armazenagem } \\
\text { e/ou transporte e distribuição }\end{array}$ & 31 & 37 & 34 & 18 & 10 \\
\hline Total Parcial & 110 & 109 & 91 & 55 & 25 \\
\hline \multicolumn{6}{|c|}{ Em relação à utilização do produto indique o grau de preocupação com: } \\
\hline Vida útil do produto & 59 & 52 & 11 & 8 & 0 \\
\hline Necessidade de energia & 53 & 43 & 24 & 7 & 3 \\
\hline Potencial contaminação do meio ambiente & 47 & 44 & 32 & 5 & 2 \\
\hline Embalagem (tipo e/ou volume) & 32 & 41 & 36 & 17 & 4 \\
\hline Total Parcial & 191 & 180 & 103 & 37 & 9 \\
\hline \multicolumn{6}{|c|}{ Em relação à pós-utilização do produto indique o grau de preocupação com: } \\
\hline Possibilidade de reutilização & 30 & 54 & 32 & 13 & 1 \\
\hline Potencialidade de reaproveitamento de componentes & 25 & 47 & 36 & 20 & 2 \\
\hline Possibilidade de reciclagem & 30 & 47 & 35 & 14 & 4 \\
\hline Total Parcial & 85 & 148 & 103 & 47 & 7 \\
\hline \multicolumn{6}{|c|}{ Em relação ao descarte do produto indique o grau de preocupação com: } \\
\hline Periculosidade ou toxidade & 83 & 29 & 13 & 3 & 2 \\
\hline Volume de material (incluindo embalagem) & 33 & 39 & 36 & 19 & 3 \\
\hline Biodegradabilidade & 31 & 43 & 38 & 12 & 6 \\
\hline Total Parcial & 147 & 111 & 87 & 34 & 11 \\
\hline Total geral & 593 & 643 & 443 & 207 & 64 \\
\hline
\end{tabular}

Fonte: Pesquisa aplicada (2006).

Verifica-se que a percepção ambiental não está associada ao grau de educação ambiental que é recebida. Esta conclusão baseia-se somente na interferência gerada pelas disciplinas direcionadas às questões ambientais, não considerando, portanto, outras fontes de informações e conhecimentos da amostra.

Este estudo de caso corrobora outros resultados de pesquisas, constatando-se que a educação ambiental nas escolas brasileiras é deficiente e carece ser melhorada. Assim, pode-se afirmar que não basta a inclusão da educação ambiental nas escolas, é preciso informar o consumidor para que as mudanças de comportamento se estabeleçam, já que a mídia é a principal fonte de informações sobre as questões ambientais para os dois grupos da amostra pesquisada.

Essas informações são úteis para conhecer como o universitário se posiciona, enquanto consumidor e o que ele leva em consideração ao escolher determinado produto. Os estudantes são formadores de opinião e podem
Tabela 10. Classificação do grau de preocupação em relação às etapas da ACV.

\begin{tabular}{lc}
\hline $\begin{array}{l}\text { Grau de preocupação em } \\
\text { relação às etapas da } \mathbf{A C V}\end{array}$ & Valores \\
\hline A) Forte preocupação & Entre 3,3 e 4,0 \\
B) Frequente preocupação & Entre 2,5 e 3,2 \\
C) Mediana preocupação & Entre 1,7 e 2,4 \\
D) Fraca preocupação & Entre 0,9 e 1,6 \\
E) Nenhuma preocupação & Até 0,8 \\
\hline
\end{tabular}

Fonte: Pesquisa aplicada (2006).

contribuir para minimizar a poluição ambiental mudando seu comportamento de compra.

Para as organizações, essas informações são úteis para nortear as ações empresariais no que tange ao incremento ou criação de novos produtos cuja demanda depende da difusão da percepção ecológica, podendo levar o consumidor a valorizar empresas que tenham um padrão de produção sustentável e a alterar seu próprio padrão de consumo. 
Embora os investimentos em gestão ambiental sejam motivados por fatores competitivos, existem outros fatores que determinam a realização de tal investimento. Assim, o empresário que antes via a questão ambiental como um fator de aumento de custos do processo produtivo, depara-se com vantagens competitivas e oportunidades econômicas de uma gestão responsável dos recursos naturais.

O fabricante que desenvolver instrumentos de informação, divulgando os benefícios ambientais proporcionados pelo consumo de seu produto, além de estimular a mudança nos padrões de consumo, pode torna-se mais competitivo. A ênfase na mudança dos padrões de consumo e nos processos de produção deve ser vista como uma forma de fortalecer a ação política do cidadão, como um compromisso ético, consciência e responsabilidade quanto aos impactos ambientais que as escolhas e condutas do consumidor podem causar no meio ambiente.

\title{
Perception and environmental behavior of university students considering their level of environmental education
}

\begin{abstract}
The aim of this study is to investigate whether the environmental perception is associated to the level of environmental education a person has gotten. This paper presents a comparable study between university students who have and those who do not have taken environmental education disciplines as part of the university course curriculum. The tool used in the analysis was adapted from the VAPERCOM model. The importance of this study is the evaluation of consumers' behavior considering the environmental perception variable contributing to the organizational management according to the expectations and evaluations of consumers.
\end{abstract}

Keywords: Environmental education. Behavior. Perception.

\section{Referências bibliográficas}

ALMEIDA Jr., A. R.; ANDRADE, T. N. Publicidade e ambiente: alguns contornos. Ambiente \& Sociedade, v. X, n. 1, p. 107-120, 2007.

BAKER, M. J. Administração de marketing. Rio de Janeiro: Elsevier, 2005.

BENNETT, P. D.; KASSARJIAN, H. H. O comportamento do consumidor. São Paulo: Atlas, 1975.

BERTOLINI, G. R. F.; POSSAMAI, O. Proposta de instrumento de mensuração do grau de consciência ambiental, do consumo ecológico e dos critérios de compra dos consumidores. Revista de Ciência e Tecnologia, v. 13, n. 25-26, p. 17-25, 2005.

BOWDITCH, J. L.; BUONO, A. F. Elementos de comportamento organizacional. São Paulo: Pioneira, 1992.

BRANDALISE, L. T. Modelo suporte à gestão organizacional com base no comportamento do consumidor considerando sua percepção a variável ambiental nas etapas da Análise do Ciclo de Vida do produto. 2006. 195 f. Tese (Doutorado em Engenharia de Produção) - Universidade Federal de Santa Catarina, Florianópolis.

BRANDALISE, L. T. A percepção do consumidor na Análise do Ciclo de Vida do produto: um modelo de apoio à gestão empresarial. Cascavel: Edunioeste, 2008.

ENGEL, J. F.; BLACKWELL, R. D.; MINIARD, W. P. Comportamento do consumidor. 8 ed. Rio de Janeiro: LTC, 2000.
INSTITUTO AKATU. Responsabilidade social empresarial: a percepção do consumidor brasileiro. Disponível em: <http:// www.uniethos.org.br/_uniethos/documents/pesq_consum_2004. pdf>. Acesso em: 28 de Dezembro de 2005.

KOTLER, P. Administração de marketing: a edição do novo milênio. São Paulo: Prentice Hall, 2000.

LAVORATO, M. L. A. Jornal do meio ambiente. Edição de 02/02/2007. Disponível em: <www.jornaldomeioambiente.com. br>. Acesso em: 13 de Fevereiro de 2007.

MAIA, N. B.; MARTOS, H. L.; BARRELA, W. (Orgs.). Indicadores ambientais: conceitos e aplicações. São Paulo: EDUC; COMPED; INEP, 2001.

MEADOWS, D. et al. Os limites do crescimento. São Paulo: Perspectiva, 1972.

SERRANO, C. M. L. Educação ambiental e consumerismo em unidades de ensino fundamental de Viçosa-MG. 2003. 91 p. Dissertação (Mestrado em Ciência Florestal) - Universidade Federal de Viçosa, Viçosa.

TAGLIACARNE, G. Pesquisa de mercado: técnica e prática. 2 ed. São Paulo: Atlas, 1976.

UNITED NATIONS EDUCATIONAL SCIENTIF AND CULTURAL ORGANIZATION UNESCO; ORGANIZAÇÃO DAS NAÇÕES UNIDAS PARA A EDUCAÇÃO, CIÊNCIA E CULTURA. Tendências de la educación ambiental. Paris: Unesco, 1997. 


\section{Sobre os autores}

\section{Loreni Teresinha Brandalise}

Universidade Estadual do Oeste do Paraná - Unioeste

Rua Universitária, 2069, Jardim Universitário, Cascavel - PR, CEP 85819-110

e-mail: Iorenni@unioeste.br

\section{Geysler Rogis Flor Bertolini}

Universidade Estadual do Oeste do Paraná - Unioeste

Rua Universitária, 2069, Jardim Universitário, Cascavel - PR, CEP 85819-110

e-mail: geysler@unioeste.br

\section{Cláudio Antonio Rojo}

Universidade Estadual do Oeste do Paraná - Unioeste

Rua Universitária, 2069, Jardim Universitário, Cascavel - PR, CEP 85819-110

e-mail: rojo@ rojo.com.br

\section{Álvaro Guilhermo Rojas Lezana}

Universidade Federal de Santa Catarina - UFSC

Trindade, Florianópolis - SC, CEP 88040-900

e-mail: lezana@deps.ufsc.br

\section{Osmar Possamai}

Universidade Federal de Santa Catarina - UFSC

Trindade, Florianópolis - SC, CEP 88040-900

e-mail: possamai@deps.ufsc.br 